\title{
THE MYTH OF HIDDEN OVULATION: SHAPE AND TEXTURE CHANGES IN THE FACE DURING THE MENSTRUAL CYCLE
}

\author{
DR. E. OBERZAUCHER ${ }^{1}$, DR. S. KATINA ${ }^{2,3}$, MAG. S. F. SCHMEHL ${ }^{1}$, \\ MAG. I. J. HOLZLEITNER ${ }^{1}$, I. MEHU-BLANTAR ${ }^{1}$, DR. K. GRAMMER ${ }^{1, *}$ \\ ${ }^{1}$ Department of Anthropology, University of Vienna, Vienna, Austria \\ ${ }^{2}$ Department of Anthropology and Department of Mathematics and Statistics, Faculty of Science, \\ Masaryk University, Brno, Czech Republic \\ ${ }^{3}$ Department of Applied Mathematics and Statistics, Faculty of Mathematics, Physics and \\ Informatics, Comenius University, Bratislava, Slovakia
}

\begin{abstract}
In recent years, evidence has been gathered indicating increased attractiveness of female faces at the point of ovulation. In this paper, we asked what changes in facial appearance occur during menstrual cycle that lead to this shift in attractiveness. We analysed facial photographs of 20 young women with a normal cycle. We found evidence for textural changes, as well as shape changes that might account for the ovulatory peak in attractiveness. Generally, facial shape at ovulation is perceived as more attractive - and ovulating women are perceived as more attractive the closer their face shape is to the "ovulation shape". These findings support the hypothesis that attractive signals might be rooted in signals of fertility.
\end{abstract}

Keywords: ovulation, facial attractiveness, symmetry, geometric morphometric methodology

\section{INTRODUCTION}

The fact that human females do not appear to show any visible signs of ovulation unlike other primates - has led to the development of a rich theoretical body of work attempting to explain this phenomenon in terms of evolutionary constraints.

Has hidden oestrus evolved to trick males into forming a pair bond (ALEXANDER and NOONAN 1979)? Following this line of reasoning, males unaware of females' fertility would remain bonded to ensure impregnation and paternity; a female providing clues to her ovulation might risk losing male investment (TRIVERS 1972). Or, quite the opposite, has hidden oestrous arisen to increase paternal insecurity to allow females to "escape the negative consequences of being pawns in marriage games” (GRAY and WOLFE 1983)? Once monogamy is established, an optional female strategy would be to copulate outside their long-term relationships,

*Address for correspondence: ${ }^{1}$ Dr. E. OBERzAUChER, University of Vienna Vienna, Austria, e-mail: elisabeth.oberzaucher@univie.ac.at. ${ }^{2}$ DR. S. KATINA, Department of Anthropology and Department of Mathematics and Statistics, Faculty of Science, Masaryk University, Brno, Czech Republic, e-mail: stanislav.katina@gmail.com ${ }^{3}$ MAG. S. F. SCHMEHL, University of Vienna, Department of Anthropology, e-mail: susanne.schmehl@univie.ac.at. ${ }^{1}$ MAG. I. J. HolzLEITNER, University of Vienna, Dept. of Anthropology, e-mail: iris.holzleitner@univie.ac.at. ${ }^{1}$ I. MEHUBlantar, University of Vienna Vienna, Austria, e-mail: womme@gmx.at. ${ }^{1}$ Dr. K. Grammer, University of Vienna, Dept. of Anthropology, e-mail: grammer@univie.ac.at 
thus obtaining superior genes for their offspring while ensuring paternal investment by her long-term partner (BELLIS and BAKER 1991). Indeed, increased extra-pair copulations coincide with an increase in females' self-reported arousal to sexual stimuli (LUSCHEN and PIERCE 1972), peaks in sexual receptivity (ADAMS, GOLD and BURT 1978), and an increased amount of attraction to, and fantasies about, men who are not their primary partners. Yet another hypothesis speculates that signals of oestrus might have been reduced to counter infanticide by increased paternal uncertainty (HRDY 1981). Unfortunately, these theories cannot be tested empirically.

In recent years, evidence has accumulated indicating that women's mate preferences change during ovulation (ROBERTS et al. 2004). In this context, the term hormone-mediated adaptive design has been introduced: In their fertile phase, women prefer more masculine features than in their non-fertile phase (JOHNSTON et al. 2001). In addition, male body odour smells most intense and least unpleasant to women at ovulation (DOTY et al. 1975; SINGH and BRONSTAD 2001).

Female behaviour changes, too: Walking style becomes more feminine (GRAMMER et al. 2003), and women dress more 'sexily' during the fertile window of their cycle (GRAMMER, RENNINGER and FISCHER 2004). Not only do women behave differently, they are also perceived differently: Several recent studies show that women are judged to be more attractive when in their fertile phase of the menstrual cycle (ROBERTS et al. 2004; LAW SMITH et al. 2006).

The fact that women lack ostentatious sexual swellings does not imply that women do not signal their fertility status. Both the sexual swellings in primates, as well as the shifts in human behaviour and facial appearance during ovulation, apparently make females more attractive to males. Thus, we think the term 'concealed ovulation' to be inappropriate and misleading.

The fact that women are most attractive in the fertile window of their cycle (ROBERTS et al. 2004; LAW SMITH et al. 2006) causes us to question whether we have been approaching the whole topic from the wrong end: Traits associated with attractiveness could well be perceived as attractive because they are signals of ovulation. Instead of ovulation being hidden in humans, signals of ovulation might have spread over the whole menstrual cycle. Thus, fertility signals may have become part of overall attractiveness.

Female attractiveness is characterised by a number of aspects, such as reduced fluctuating asymmetry, markers of hormone levels, skin coloration, and neoteny markers. According to the parasite theory of sexual selection (HAMILTON and ZUK 1982), the absence of anomalies in ontogeny shows 'developmental stability': The inability to cope with environmental and genetic perturbations is for example reflected in elevated levels of fluctuating asymmetry (GANGESTAD, THORNHILL and Yeo 1994; Grammer and ThORNHILL 1994; THORNHILl and Moller 1998), a symmetric face presumably indicates high immune competence (THORNHILL and GANGESTAD 1993). Preferences for averageness have been linked to heterozygosity, which represents a larger buffer against pathogens. 
In addition, immune competence is highly relevant because the steroid reproductive hormones responsible for the development of attractive, secondary sexual traits, may negatively affect immunological functions (FOLSTAD and KARTER 1992). Thus, markers developed with the help of high sex hormone levels may signal the ability of the immune system to deal with the deteriorating effect of oestrogen (SERVICE 1998). The display of handicaps such as hormone markers can signal the ability to meet the costs imposed by this handicap. As another example, ZAHAVI and ZAHAVI (1997) discuss red cheeks and lips. The red colouring is a result of peripheral blood circulation below the skin, which cannot be kept up in a cold environment or during times of illness.

Skin texture is also known to affect the attractiveness of faces, and it too seems to signal fitness. ROBERTS et al. (2005) found skin homogeneity and attractiveness to be positively associated with heterozygosity in MHC-genes. MATTS et al. (2007) found that a different skin can make the same face look 20 years older. Skin darkens in pregnancy, under the influence of hormonal contraception, which has been taken to assume that paler skin - found to be attractive in previous studies - might be an indicator of neoteny (FROST 1988).

JONES (1996) showed that female faces exhibiting certain - neotenous - facial proportions - small lower face, lower jaw and nose, and large lips - are perceived as more attractive. The strong association between youth and fecundity in adult females supposedly led to the male preference for facial markers of high, age-related fecundity. Women's faces are attractive when they possess small lower facial features, especially a gracile jaw, and large lips, which manifest under the influence of oestrogen. These features may also be signals of nulliparous status (SYMONS 1995).

In the present study we address the question why ovulating women are perceived as more attractive. Can increased attractiveness at ovulation be linked to measurable parameters? And, are those parameters similar to those already known to be positively linked to female attractiveness?

\section{METHODS}

20 females aged 19 to $31(23.35 \pm 3.15)$ were photographed every day at the same time throughout an entire cycle after giving informed consent. Ovulation was detected using ovulation kits. For this investigation we used the photo from the first day of ovulation and a luteal picture from 14 days after ovulation.

In a two-alternative forced choice task, 15 men (aged $24.20 \pm 4.57$ ) and 10 women (aged $26.80 \pm 4.49$ ) were asked to identify from each ovulatory/luteal pair the image which was rated more highly on a number of features (attractive, healthy, sexy, sociable, trustworthy, young, and likeable). Ovulatory and luteal images were presented simultaneously on a computer screen in random order, with no indication of the image types. 
The statistical analyses were performed in $R$ software (R DEVELOPMENT, CORE TEAM 2010). The results of hypotheses testing were considered as statistically significant at $p$-value $<0.05$. All $p$-values were calculated by a permutation method (number of permutations $=5000$ ).

The odds that the face in ovulatory state was rated more positively for a particular item was tested by a permutation Chi-square test. The null hypothesis is as follows: odds are less than or equal to 1 , where 1 means that ovulatory and luteal state were chosen with the same probability.

We analysed the morphological changes using geometric morphometrics. On the facial photographs, we measured Cartesian coordinates of 46 anthropological landmarks and 26 semilandmarks (6 on the upper and lower outline of each eyebrow, 7 on each half of the lower face, from the ear lobe to the turning point of left and right chin, Table 1, Fig. 1).

Table 1. Definition of (semi)landmarks; left/right orientation - with respect to the observer *excluded from the analysis

\begin{tabular}{|c|c|c|}
\hline $1^{*}$ & Forehead right & The right corner of the forehead, located in the hairline \\
\hline $2^{*}$ & Trichion & The mid point of the hairline \\
\hline $3^{*}$ & Forehead left & The left corner of the forehead, located in the hairline \\
\hline 4 & Superciliare laterale right & The most lateral point of the right eyebrow \\
\hline 5 & Upper eyebrow right & \multirow{3}{*}{ Semilandmarks } \\
\hline 6 & Upper eyebrow right & \\
\hline 7 & Upper eyebrow right & \\
\hline 8 & Superciliare mediale right & The most medial point of the right eyebrow \\
\hline 9 & Lower eyebrow right & \multirow{3}{*}{ Semilandmarks } \\
\hline 10 & Lower eyebrow right & \\
\hline 11 & Lower eyebrow right & \\
\hline 12 & Superciliare mediale left & The most medial point of the left eyebrow \\
\hline 13 & Upper eyebrow left & \multirow{3}{*}{ Semilandmarks } \\
\hline 14 & Upper eyebrow left & \\
\hline 15 & Upper eyebrow left & \\
\hline 16 & Superciliare laterale left & The most lateral point of the left eyebrow \\
\hline 17 & Lower eyebrow left & \multirow{3}{*}{ Semilandmarks } \\
\hline 18 & Lower eyebrow left & \\
\hline 19 & Lower eyebrow left & \\
\hline 20 & Exocanthion right & The outer corner of the right eye fissure where the eyelids meet \\
\hline 21 & Iris top right & $\begin{array}{l}\text { The highest point of the right iris; if not visible, point is located } \\
\text { on the approximated elongation of the circumference of the pupil }\end{array}$ \\
\hline
\end{tabular}


Table 1. (Continue)

\begin{tabular}{|c|c|c|}
\hline 22 & Endocanthion right & $\begin{array}{c}\text { The right inner corner of the right eye fissure where the eyelids } \\
\text { meet }\end{array}$ \\
\hline 23 & Iris bottom right & $\begin{array}{l}\text { The lowest point of the right iris; if not visible, point is located } \\
\text { on the approximated elongation of the circumference of the pupil }\end{array}$ \\
\hline 24 & Iris laterale right & The most lateral point of the right iris \\
\hline 25 & Pupil right & The mid point of the right pupil \\
\hline 26 & Iris mediale right & The most medial point of the right iris \\
\hline 27 & Endocanthion left & The inner corner of the left eye fissure where the eyelids meet \\
\hline 28 & Iris top left & $\begin{array}{l}\text { The highest point of the left iris; if not visible, point is located on } \\
\text { the approximated elongation of the circumference of the pupil }\end{array}$ \\
\hline 29 & Exocanthion left & The outer corner of the left eye fissure where the eyelids meet \\
\hline 30 & Iris bottom left & $\begin{array}{l}\text { The lowest point of the left iris; if not visible, point is located on } \\
\text { the approximated elongation of the circumference of the pupil }\end{array}$ \\
\hline 31 & Iris mediale left & The most medial point of the left iris \\
\hline 32 & Pupil left & The mid point of the left pupil \\
\hline 33 & Iris laterale left & The most lateral point of the left iris \\
\hline 34 & Alare origin right & $\begin{array}{l}\text { The most inner point of the right ala of the nose; or elongation of } \\
\text { the nasolabial folds on right ala of the nose }\end{array}$ \\
\hline 35 & Alare right & The most lateral point on the right nasal ala \\
\hline 36 & $\begin{array}{c}\text { Columella apex } \\
\text { (columella breakpoint, } \\
\text { nostril top point) right }\end{array}$ & $\begin{array}{l}\text { (The most anterior or) the highest point on the columella crest at } \\
\text { the apex of the right nostril }\end{array}$ \\
\hline 37 & Subnasale & $\begin{array}{l}\text { On the local midline of the junction formed by the lower border } \\
\text { of the nasal septum (the partition that divides the nostrils) and the } \\
\text { cutaneous portion of the upper lip }\end{array}$ \\
\hline 38 & $\begin{array}{c}\text { Columella apex } \\
\text { (columella breakpoint, } \\
\text { nostril top point) left }\end{array}$ & $\begin{array}{l}\text { (The most anterior or) the highest point on the columella crest at } \\
\text { the apex of the left nostril }\end{array}$ \\
\hline 39 & Alare left & The most lateral point on the left nasal ala \\
\hline 40 & Alare origin left & $\begin{array}{l}\text { Most inner point of the left ala of the nose; or elongation of the } \\
\text { nasolabial folds on left ala of the nose }\end{array}$ \\
\hline 41 & Cheilion right & $\begin{array}{l}\text { The right corner of the mouth where the outer edges of the upper } \\
\text { and lower vermilions meet }\end{array}$ \\
\hline 42 & Upper lip right & $\begin{array}{l}\text { The point in the middle of Labiale superius (44) and right Cheil- } \\
\text { ion (41) }\end{array}$ \\
\hline 43 & Crista philtri right & $\begin{array}{l}\text { The point on the right crest of the philtrum, i.e. the vertical } \\
\text { groove in the median proportion of the upper lip, located on the } \\
\text { vermilion border }\end{array}$ \\
\hline 44 & Labiale superius & $\begin{array}{l}\text { The philtrum mid point, located on the vermilion border of the } \\
\text { upper lip }\end{array}$ \\
\hline
\end{tabular}


Table 1. (Continue)

\begin{tabular}{|c|c|c|}
\hline 45 & Crista philtri left & $\begin{array}{l}\text { The point on the crest of the left philtrum, i.e. the vertical groove } \\
\text { in the median proportion of the upper lip, located on the vermil- } \\
\text { ion border }\end{array}$ \\
\hline 46 & Upper lip left & $\begin{array}{l}\text { The point in the middle between Labiale superius (44) and left } \\
\text { Cheilion (47) }\end{array}$ \\
\hline 47 & Cheilion left & $\begin{array}{c}\text { The left corner of the mouth where the outer edges of the upper } \\
\text { and lower vermilions meet }\end{array}$ \\
\hline 48 & Lower lip left & $\begin{array}{l}\text { The point in the middle between Labiale inferius (49) and left } \\
\text { Cheilion (47) }\end{array}$ \\
\hline 49 & Labiale inferius & The mid point of the vermilion border of the lower lip \\
\hline 50 & Lower lip right & $\begin{array}{l}\text { The point in the middle between Labiale inferius (49) and right } \\
\text { Cheilion (41) }\end{array}$ \\
\hline 51 & Cleft right & $\begin{array}{c}\text { The point between Stomion (52) and right Cheilion (41), exactly } \\
\text { on the right cleft between upper and lower lip }\end{array}$ \\
\hline 52 & Stomion & The mid point of the labial fissure \\
\hline 53 & Cleft left & $\begin{array}{l}\text { The point between Stomion (52) and left Cheilion (47), on the } \\
\text { left cleft between upper and lower lip }\end{array}$ \\
\hline 54 & Zygion right & The most lateral point on the right zygomatic arch \\
\hline 55 & Otobasion inferius right & $\begin{array}{c}\text { The lowest point of attachment of the right ear lobe to the cheek, } \\
\text { which determines the lower border of right ear insertion }\end{array}$ \\
\hline 56 & Lower face right & \multirow{7}{*}{ Semilandmarks } \\
\hline 57 & Lower face right & \\
\hline 58 & Lower face right & \\
\hline 59 & Lower face right & \\
\hline 60 & Lower face right & \\
\hline 61 & Lower face right & \\
\hline 62 & Lower face right & \\
\hline 63 & Gnathion & The turning point of the right and left side of the chin \\
\hline 64 & Lower face left & \multirow{7}{*}{ Semilandmarks } \\
\hline 65 & Lower face left & \\
\hline 66 & Lower face left & \\
\hline 67 & Lower face left & \\
\hline 68 & Lower face left & \\
\hline 69 & Lower face left & \\
\hline 70 & Lower face left & \\
\hline 71 & Otobasion inferius left & $\begin{array}{l}\text { The lowest point of attachment of the left ear lobe to the cheek, } \\
\text { which determines the lower border of left ear insertion }\end{array}$ \\
\hline 72 & Zygion left & The most lateral point on the left zygomatic arch \\
\hline
\end{tabular}




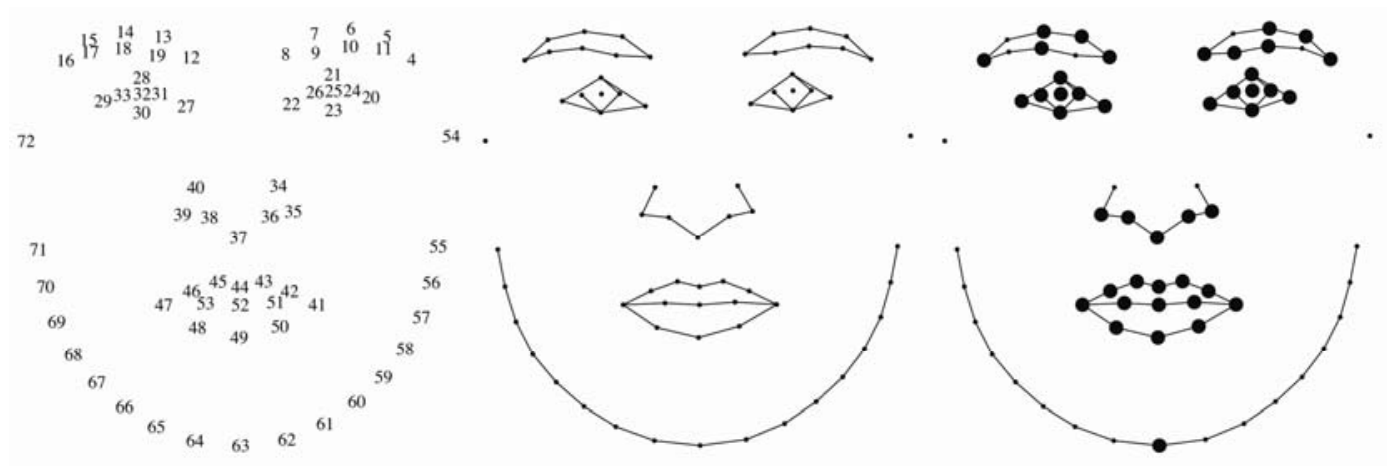

Fig. 1. Design of the (semi)landmarks (left and middle; numbers correspond to Table 1 ) and statistically significant (semi)landmarks $(\cdot:$ p-values $<0.05$, not adjusted by any multiple post-hoc correction, (semi)landmarkwise matched-pair Goodall F-test)

We calculated the Procrustes shape coordinates using a generalized Procrustes analysis (BOOKSTEIN 1991). Firstly, the centroid of each (semi)landmark configuration was found, and its root mean square distance to the (semi)landmarks computed; this is called centroid size (CS). Secondly, the forms were re-scaled to CS = 1, the centroids superimposed, and the forms rotated around the common centroid, until the sum of squared distances between corresponding (semi)landmarks was a minimum over all such rotations. This resulted in Procrustes shape coordinates. Equidistantly marked semilandmarks were slid with respect to reference curves using bending energy. Sliding was performed iteratively on tangents, in a locally linear way, to get geometrically homologous semilandmarks on the curves.

Hypotheses about mean shape differences between ovulatory and luteal states were tested by permutation matched-pair Goodall F-test and, additionally, for visualisation purposes, by (semi)landmarkwise matched-pair Goodall F-test, where p-values were not adjusted by any multiple post-hoc correction. The aim of pointwise statistical inference was only to visualize the statistical and biological signal present in the data. Additionally we investigated fluctuating asymmetry in both states (luteal and ovulatory) separately by permutation one-sample MardiaBookstein-Moreton test (MARDIA, BOOKSTEIN and MORETON 2000). The level of asymmetry was determined as the sum of squares of differences between original and reflected forms.

A shape space matched-pair principal components analysis (PCA, also called relative warp analysis, RWA) of the covariance matrix of approximate tangent Procrustes shape coordinates (centered Procrustes shape coordinates, Procrustes fit coordinates) was conducted in several forms: 1) PCA in full shape space, 2) PCA in subspace of global bending patterns, and 3) PCA in subspace of local bending patterns. Variability was decomposed into orthogonal components and, subsequently, these components of shape variation were examined (BOOKSTEIN 1991) and the 
main direction and size of the shape changes between luteal and ovulatory state were identified. In the subspace of the first two PCs, a permutation one-sample test was used to assess whether PC scores were significantly different from zero (in which case the null hypothesis that ovulatory and luteal faces do not differ in the particular PC subspace was rejected).

With a symmetrical two-block partial least square (PLS) analysis (BOOKSTEIN 1994; SAMPSON, STREISSGUTH, BARR and BOOKSTEIN 1989) we investigated the correspondence between the set of centered Procrustes shape coordinates (block 1), and attraction variables and degree of fluctuating asymmetry (block 2). The multivariate association between both blocks can be expressed by means of Pearson product-moment correlation coefficients of singular warp (SW) scores.

Both PCA and PLS find low-dimensional linear combinations of highdimensional measurements by adapting one singular value decomposition of common and cross-block covariance matrices, respectively. The biologically meaningful signal was investigated in the first two principal components (PCs) and the first SW.

The visualisation of shape change from source to target was performed by thin plate spline (TPS) deformation grids (BOOKSTEIN 1991). The Procrustes mean shape was chosen as a reference (source) form (Fig. 1). To quantify mean shape differences, luteal and ovulatory mean shapes were chosen as targets. In both, PCA and PLS, the matrix of scaled eigenvectors (PC loadings and singular vectors, resp.) was used in the same way. If necessary, TPS deformation grids were extrapolated (magnified) in a particular direction to ease the visualisation.

The analysis of skin texture homogeneity was carried out with co-occurrence matrices from a 50×50 pixels sized patch from the left cheek (HARALICK, SHANMUGAM and DINSTEIN 1973). The co-occurrence matrix allows measuring the spatial interrelationships of grey tones in a textural pattern to be measured and this provides objective measurements for skin texture. The colour characteristics in skin textures where calculated in a HSV-colour space as an average over the whole patch. These procedures have been employed successfully in previous studies (FINK, GRAMMER and MATTS 2006; GrAMMER and THORNHILL 1994; MATTS, FINK, GRAMMER and BURQUEST 2007).

Hypotheses about mean differences between ovulatory and luteal state in particular texture variables were tested by permutation matched-pair student's t-test. The null hypothesis was one-sided with the mean difference being less than or equal to zero.

Reliability of landmarks was calculated for both $x$ - and $y$-coordinates simultaneously as total variance (trace of covariance matrix of particular landmark). It reflects intra- and inter-observer error scaled by sample total variance $(n=20)$. Median intra-observer error was $3.60 \%$, median inter-observer error $6.61 \%$. The less reliable measurements were, not surprisingly, Type II and III landmarks (BooKSTEIN, 1991), namely forehead ${ }^{*}$, trichion ${ }^{*}$, superciliare, alare, alare origin, columella apex, iris mediale and laterale, and gnathion " (excluded from the analyses). 


\section{RESULTS}

Ovulatory faces were chosen significantly more often as being more attractive, healthy, sexy, sociable, trustworthy, young, and likeable than luteal faces (Table 2).

Table 2. Frequencies of ovulatory face picture being chosen in the forced choice task

\begin{tabular}{|c|c|c|c|c|}
\hline item & $\begin{array}{c}\text { absolute } \\
\text { frequency }\end{array}$ & $\begin{array}{c}\text { relative frequency in } \% \pm \\
\text { sd }\end{array}$ & $\begin{array}{c}\text { Chi-square } \\
\text { stat }\end{array}$ & p-value \\
\hline attractive & 288 & $57.60 \pm 2.21$ & 11.25 & $<0.001$ \\
\hline healthy & 306 & $61.20 \pm 2.18$ & 24.64 & $<0.001$ \\
\hline sexy & 301 & $60.20 \pm 2.19$ & 20.40 & $<0.001$ \\
\hline sociable & 273 & $54.60 \pm 2.23$ & 4.05 & 0.022 \\
\hline trustworthy & 275 & $55.00 \pm 2.22$ & 4.80 & 0.014 \\
\hline young & 293 & $58.60 \pm 2.20$ & 14.45 & $<0.001$ \\
\hline likeable & 282 & $56.40 \pm 2.22$ & 7.94 & 0.002 \\
\hline
\end{tabular}

Ovulatory and luteal faces were significantly different in PC2 of full shape space $(p=0.002)$, and in PC1 and PC2 of local bending patterns ( $p=0.001$ and $p=$ 0.032, resp.). In all PCs (see Fig. 2), the lower face is more robust in the luteal phase, the nose is broader, and the eyebrows are more pronounced; in the ovulatory phase, the lips are fuller and the whole face is more gracile (Fig. 2).

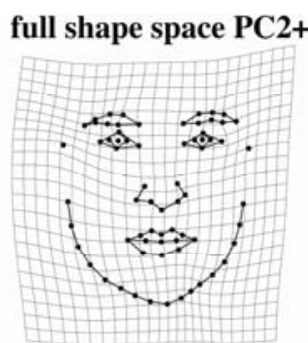

ovulatory face

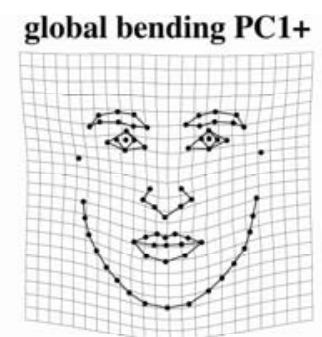

ovulatory face

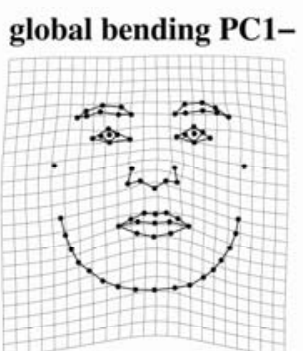

luteal face

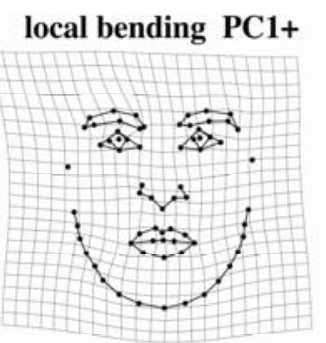

ovulatory face

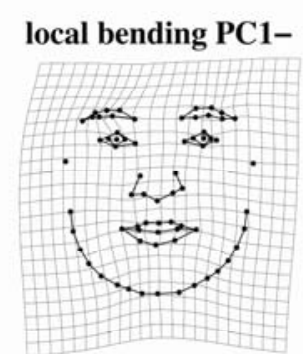

luteal face

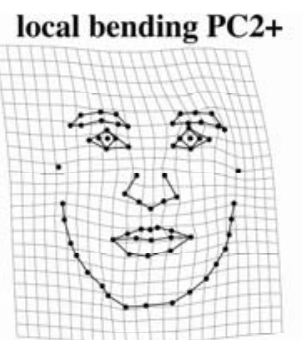

ovulatory face

local bending PC2-

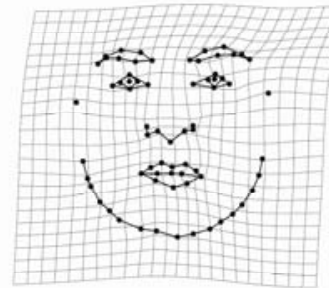

luteal face

Fig. 2. TPS deformation grids; PCA in full shape space (first column; PC2, explained variance $12.17 \%$ ); PCA for global bending patterns (second column; PC1, 47.16\%), and PCA for local bending patterns (last two columns; PC1 and PC2, 14.46\% and 12.24\%, resp.) 
Shape corresponds to attractiveness ratings in more or less the same direction: Among ovulatory faces, those which have the least deviation from the average ovulatory face are perceived as most attractive, whereas those whose shape is similar to the average luteal face are perceived as least attractive (Fig. 3).

SW1+

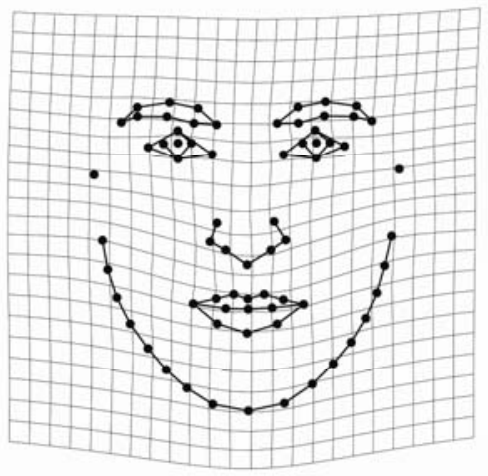

most attractive face
SW1-

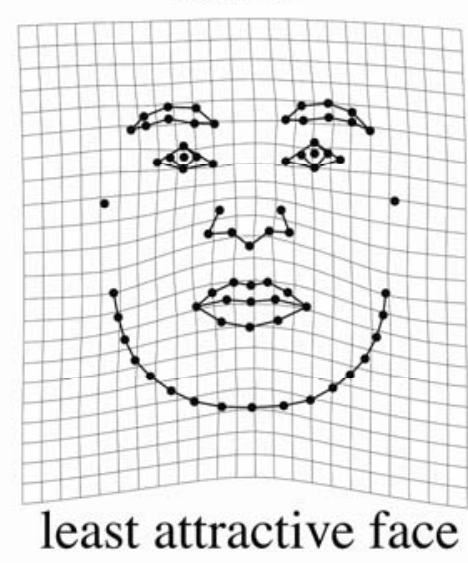

Fig. 3. TPS deformation grids of PLS in SW1 (ovulatory faces only, explained variance $54.84 \%$, Pearson product-moment correlation coefficient of attractiveness ratings and shape coordinates $=0.622$, calculated based on SW1 scores)

Ovulatory faces were not significantly asymmetric $(p=0.4)$, while luteal faces were strongly asymmetric $(p<0.0001)$.

Ovulatory skin had significantly lower hue (it is redder), lower contrast, and increased homogeneity compared to luteal skin (Table 3).

Table 3. Results of the texture analysis

\begin{tabular}{|c|c|c|c|c|}
\hline item & mean ovulatory \pm sd & mean luteal \pm sd & t-stat & p-value \\
\hline homogeneity & $0.257 \pm 0.028$ & $0.243 \pm 0.025$ & 2.936 & 0.008 \\
\hline correlation & $7.020 \times 10^{11} \pm 2.520 \times 10^{11}$ & $8.13 \times 10^{11} \pm 2.210 \times 10^{11}$ & -2.097 & 0.050 \\
\hline hue & $0.026 \pm 0.059$ & $0.029 \pm 0.050$ & -2.875 & 0.010 \\
\hline
\end{tabular}

\section{DISCUSSION}

Our findings confirm earlier studies insofar as facial pictures of ovulatory women were chosen significantly more often as being more attractive, healthy, sexy, sociable, trustworthy, young, and likeable than luteal faces. We could identify the shape 
changes that occur between the luteal and ovulatory state. The lower face is more robust in the luteal phase, the nose is broader, and the eyebrows are more pronounced. This corresponds to what have been described as masculine features in the literature (ROBERTS et al. 2004). In the ovulatory phase the lips are fuller and the whole face is less robust. Fuller lips and a fragile lower face have been previously associated with youthfulness and high levels of oestrogen (GRAMMER et al. 2003; SYMONS 1995). The increased redness of the face is probably due to higher peripheral blood circulation.

While we took all measures to ensure that the faces were photographed in exactly frontal position, any two-dimensional approach is vulnerable to tilting effects. Part of the shape changes we find might be due to changes in head pose, i.e. the luteal faces might be tilted back more. In order to rule out this possibility, we will collect 3D data as a next step, which is not affected by head pose.

The findings of our study support the idea that some characteristics of what we perceive as an attractive female face are actually synonymous to signals of ovulation. Thus, the notion of hidden ovulation has to be challenged: First, as there are detectable changes in the appearance of the female face at the point of ovulation, it cannot be considered hidden. Second, the signal value of those characteristics has to be reinvestigated: What we perceive as being attractive might just signal ovulation, conveying no information beyond the hormonal state.

\section{ACKNOWLEDGMENT}

Statistical analyses were supported by VEGA grant Nr. 2/0038/12 to SK.

\section{REFERENCES}

Adams, D.B., Gold, A.R. and BurT, A.D. (1978): Rise in female initiaed sexual activity at ovulation and its suppression by oral contraceptives. New England Journal of Medicine, 299, 1145-1150.

Alexander, R. and Noonan, K. (1979): Concealment of ovulation, parental care, and human social evolution. In: Chagnon, N.A., Irons, W.G. (eds): Evolutionary Biology and Human Social Behavior: an anthropological perspective. North Scituate, MA: Duxbury Press, pp. 436-453.

Bellis, M. and BAKER, R. (1991): Do females promote sperm competition? Data for humans. Animimal Behavior, 40(5), 997-999.

Bookstein, F.L. (1991): Morphometric Tools for Landmark Data: Geometry and Biology. Cambridge: Cambridge University Press.

Bookstein, F.L. (1994): Partial least squares: a dose-response model for measurement in the behavioral and brain sciences. Psychology 5, 1-10.

Doty, R.L., Ford, M., Preti, G. and Huggins, G.R. (1975): Changes in intensity and pleasantness of human vaginal odors during the menstrual cycle. Science, 190(4221), 13161318. 
FinK, B., Grammer, K., and MatTs, P.J. (2006): Visible skin color distribution plays a role in the perception of age, attractiveness, and health in female faces. Evol. Hum. Behav. 27(6), $433-442$.

Folstad, I. and KARTER, A.J. (1992): Parasites, bright males, and the immunocompetence handicap. Am. Nat., 139(3), 603-622.

Frost, P. (1988): Human skin color: A possible relationship between its sexual dimorphism and its social perception. Perspectives in Biology and Medicine, 32(1), 38-58.

Gangestad, S.W., Thornhill, R. and Yeo, R.A. (1994): Facial attractiveness, developmental stability, and fluctuating asymmetry. Ethology and Sociobiology, 15(2), 73-85.

Grammer, K. and ThORNHILL, R. (1994): Human (Homo sapiens) facial attractiveness and sexual selection - The role of symmetry and averageness. Journal of Comparative Psychology, 108(3), 233-242.

Grammer, K., Keki, V., Striebel, B., AtZmüller, M. and Fink, B. (2003): Bodies in motion: a window to the soul. In: Voland, E., Grammer, K. (eds) Evolutionary Aesthetics. Heidelberg, Berlin, New York: Springer, pp 295-324.

Grammer, K., RENNINGER, L. and FISCHER, B. (2004): Disco clothing, female sexual motivation, and relationship status: Is she dressed to impress? Journal of Sex Research, 41(1), 66-74.

GrAy, J.P. and WOLFE, L.D. (1983): Human female sexual cycles and the concealment of ovulation problem. Journal of Social and Biological Structures, 6, 345-352.

HAmilton, W.D. and ZuK, M. (1982): Heritable true fitness and bright birds - A role for parasites. Science, 218(4570), 384-387.

Haralick, R.M., Shanmugam, K., and Dinstein, I. (1973): Textural features for image classification. IEEE Trans. Syst. Man Cybern. SMC 3(6), 610-621.

HRDY, S.B. (1981): The Woman that Never Evolved. Cambridge: Harvard University Press.

Johnston, V.S., Hagel, R., Franklin, M., Fink, B. and Grammer, K. (2001): Male facial attractiveness: evidence for hormone-mediated adaptive design. Evolution and Human Behavior, 22(4), 251-267.

JoNES, D. (1996): An evolutionary perspective on physical attractiveness. Evolutionary Anthropology, 5(3), 97-109.

Law Smith, M.J., Perrett, D.I., Jones, B.C., Cornwell, R.E., Moore, F.R., Feinberg, D.R., Boothroyd, L.G., Durrani, S.J., Stirrat, M.R., Whiten, S., Pitman, R.M. and Hillier, S.G. (2006): Facial appearance is a cue to oestrogen levels in women. Proceedings of the Royal Society B, 273(1583), 135-140.

Luschen, M.E. and PIERCE, D.M. (1972): Effect of menstrual cycle on mood and sexual arousability. Journal of Sex Research, 8(1), 41-47.

Mardia, K.V., Bookstein, F.L., and Moreton, I.J. (2000): Statistical assessment of bilateral symmetry of shapes. Biometrika 87(2), 285-300.

Matts, P.J., Fink, B., Grammer, K. and Burquest, M. (2007): Color homogeneity and visual perception of age, health, and attractiveness of female facial skin. Journal of the American Academy of Dermatoogy., 57 (6), 977-984.

R Development Core Team (2010): R: A Language and Environment for Statistical Computing (R Foundation for Statistical Computing, Vienna, Austria).

Roberts, S.C., Havlicek, J., Flegr, J., Hruskova, M., Little, A.C., Jones, B.C., Perrett, D.I. and Petrie, M. (2004): Female facial attractiveness increases during the fertile phase of the menstrual cycle. Proceedings of the Royal Society B, 271, 270-272.

Roberts, S.C., Little, A.C., Morris Gosling, L., Perrett, D.I., Jones, B.C., Penton-Voak, I. and PETRIE, M. (2005): MHC-heterozygosity and human facial attractiveness. Evolution and Human Behavior, 26(3), 213-226. 
SAmpson, P.D., Streissguth, A.P., BARR, H.M., and Bookstein, F.L. (1989): Neurobehavioral effects of prenatal alcohol: Part II. Partial least squares analysis. Neurotoxicol. Teratol. 11(5), 477-491.

SERVICE, R.F. (1998): New role for estrogen in cancer? Science, 279(5357), 1631-1633.

Singh, D. and Bronstad, P.M. (2001): Female body odour is a potential cue to ovulation. Proceedings of the Royal Society B, 268 (1469), 797-801.

Symons, D. (1995): Neoteny reconsidered (commentary on "Sexual selection, physical attractiveness, and facial neoteny” by D. Jones). Current Anthropology, 36, 741-743.

Thornhill, R. and GANGESTAD, S.W. (1993): Human facial beauty - Averageness, symmetry, and parasite resistance. Human Nature, 4(3), 237-269.

Thornhill, R. and Moller, A.P. (1998): The relative importance of size and asymmetry in sexual selection. Behavioral Ecology, 9(6), 546-551.

Trivers, R.L. (1972): Parental investment and sexual selection. In: Campbell, B. (ed.): Sexual Selection and the Descent of Men, 1871-1971. Chicago: Aldine Publishing Company, pp. 136-179.

Zahavi, A. and Zahavi, A. (1997): The Handicap Principle: A Missing Piece of Darwin's Puzzle. New York, Oxford: Oxford University Press. 